Article

\title{
Hybrid Carbon Nano-Fibers with Improved Oxidation Resistance
}

\author{
Saja M. Nabat Al-Ajrash * and Khalid Lafdi \\ Department of Chemical and Materials Engineering, University of Dayton, 300 College Park, Dayton, OH 45469, \\ USA; klafdi1@udayton.edu \\ * Correspondence: nabats1@udayton.edu
}

Received: 1 December 2018; Accepted: 6 January 2019; Published: 10 January 2019

\begin{abstract}
Hybrid Carbon-Silicon Carbide (C-SiC) nano-fibers were fabricated while using a mixture of polyacrylonitrile (PAN) and silicon (Si) nanoparticles as precursors. The microstructure of the material was examined using X-ray diffraction and Raman spectroscopy as a function of processing temperature and holding time. A complete transformation of $\mathrm{Si}$ to $\mathrm{SiC}$ occurred at $1250^{\circ} \mathrm{C}$. However, for heat treatments below $1000{ }^{\circ} \mathrm{C}$, three distinct phases, including $\mathrm{Si}, \mathrm{C}$, and $\mathrm{SiC}$ were present. The effect of microstructural changes, due to the heat treatment, on oxidation resistance was determined using thermogravimetric analysis (TGA). Furthermore, the char yield showed exponential growth with increasing the carbonization temperature from $850{ }^{\circ} \mathrm{C}$ to $1250{ }^{\circ} \mathrm{C}$. The holding times at higher temperatures showed a significant increase in thermal properties because of $\mathrm{SiC}$ grain growth. At longer holding times, the $\mathrm{SiC}$ phase has the function of bothcoating and reinforcing phase. Such structural changes were related to fibers mechanical properties. The tensile strength was the highest for fiber carbonized fibers at $850{ }^{\circ} \mathrm{C}$, while the modulus increased monotonically with increasing carbonization temperature.
\end{abstract}

Keywords: SiC; nanofibers; electrospinning; carbon fibers; hybrid materials

\section{Introduction}

Carbon fibers (CFs) are fibers consisting of about 90\% carbon elements with high strength (3-7 GPa) and modulus (200-500 GPa) [1-4]. They display good thermo-chemical stability in nonoxidative environments. CFs can have good thermal and electrical conductivities, and excellent creep resistance [5,6]. They have been utilized in many applications, such as aerospace [7], highway transportation [8], military [9], turbine blades [10], construction [11], energy conversion and storage [12], and self-sensing devices [13]. CFs can be fabricated using polymeric precursors, such as acrylic, cellulosic, pitch, and polyacrylonitrile (PAN) precursors $[2,14,15]$ by subsequent heat treatment.

The mechanical properties of the resulting fibers could be ultra-high modulus ( $>500 \mathrm{GPa}$ ), high modulus ( $>300 \mathrm{GPa})$, intermediate modulus (>200 GPa), or low modulus (100 GPa), depending on the initial precursor [3]. For example, polyacrylonitrile (PAN)-based carbon materials have light weight and high mechanical properties. At the same time, the low oxidation resistance of carbon fibers has been the focus of significant research. Yuanjian et al. [1] investigated the effect of oxidative environment on mechanical properties of two types of PAN-based CFs, namely CF-A (carbonized at $1350{ }^{\circ} \mathrm{C}$ ) and CF-B (carbonized at $1450{ }^{\circ} \mathrm{C}$ ). The fibers were subjected to a temperature between $400{ }^{\circ} \mathrm{C}$ to $700{ }^{\circ} \mathrm{C}$ in air. The results showed that carbon nano-fibers (CNFs) began to react with oxygen at $400{ }^{\circ} \mathrm{C}$. At $600{ }^{\circ} \mathrm{C}$, a noticeable weight loss was found, which ended with burning about $13 \%$ of total mass at $700{ }^{\circ} \mathrm{C}$. As a result, the tensile strength of fiber decreased significantly, but the modulus was found to remain constant. 
One approach to improve the properties of CFs is by utilizing multi-functional hybrid materials approach, which yields unique and novel properties as a result of synergistic combination of materials properties [16]. In the past, extensive work was performed on alloying different metals to create metal alloys which display improved properties. As lightweight becomes critical design criteria, metal alloys are being replaced with fiber reinforced composites. Theses composite showed improved physical properties with better oxidation and corrosion resistance than metals. The same strategy can be applied to CFs in order to improve its low oxidation resistance.

To fabricate carbon and silicon-based ceramics, a smart use of polymer (organic and inorganic) precursors can be utilized. It enables forming complex shapes at low temperatures [17-19]. Several studies used both carbon precursors with solid additives to produce a new nanocomposite, which leads to different material properties [20,21]. For example, PVA/Silica [22], PAN/Cu [23], and $\mathrm{MgO} / \mathrm{Al}_{2} \mathrm{O}_{3} / \mathrm{PAN}$ [24] systems were used to fabricate carbon materials composites. Silicon and silicon oxide are two important nanoparticles, which can be embedded in the polymer solution to achieve a new hybrid material. For instance, carbon/silicon $(\mathrm{C} / \mathrm{Si})$ composite nanofibers can be prepared by a judicious combination of colloid electrospinning and subsequent thermal treatments. Lee et al. [25] added $\mathrm{SiO}_{2}$ nanoparticles in a PAN to fabricate $\mathrm{SiC}$ nano-fibres using electrospinning technique. After using many characterization tools, the $\mathrm{SiO}_{2} / \mathrm{C}$ ratio played a key role in controlling the fibers morphology, structure, and properties. TGA results showed that the fibers had an excellent oxidation resistant. Saja et al. [18] used an organic/inorganic polymer blend (polydimethylsiloxane and polyacrylonitrile) to fabricate hybrid ceramic fibers. The resulting structure consists of silicon carbide $(\mathrm{SiC})$, carbon, and $\mathrm{SiOC}$. The fibers showed improved mechanical properties as compared to pristine carbon fibers.

In this paper, we report results from a study with the objective of improving carbon fibers oxidation resistance by incorporating silicon source, which after a heat treatment, converts into nano-dispersed silicon carbide, thus providing protection to oxidation, without affecting the intrinsic fiber properties. The resulted hybrid fibers have the potential for being used at higher temperatures in a wide range of applications. The carbonization temperature and time were optimized to achieve the best combination of thermal and mechanical properties.

\section{Experimental Setup}

A polyacrylonitrile copolymer (molecular weight about 100,000) with $6 \%$ methyl acrylate copolymer was acquired from scientific polymer products Inc. A $10 \mathrm{~mL}$ of $\mathrm{N}, \mathrm{N}$-Dimethylformamide (DMF) was used to dissolve PAN and form a viscous fluid. Silicon nanoparticles from Sky Spring Inc. (Houston, TX, USA), which served as a silicon source, were added to the solution. The PAN/Si ratio was $90 / 10 \mathrm{wt} \%$. However, the total weight percentage of PAN and silicon in DMF solvent was kept constant (10 wt \% Si) in $90 \mathrm{wt} \% \mathrm{DMF}$.

A magnetic agitator with a heated stage was utilized for dissolving and mixing. After stirring for $12 \mathrm{~h}$, the mixture was loaded into an electrospinning apparatus to fabricate nanofibers. The machine has a voltage controller (Stanford Research Systems, Inc. (Sunnyvale, CA, USA) Model P.S375), a pump (New Era pump systems, Inc. (Farmingdale, NY, USA) NE-300), a rotating collector (Dayton ${ }^{\circledR}$ DC Motor, 4Z145), a syringe, and a needle. The electrospinning parameters were: $15 \mathrm{kV}$ voltage, $2 \mu \mathrm{m}$ $\mathrm{min}^{-1}$ feeding rate, $25 \mathrm{~cm}$ distance from the syringe tip and collector.

The as-spun fibers were stabilized (in air) in a tube furnace, and by using a multi-step procedure, which involves:

1. Heating from $25^{\circ} \mathrm{C}$ to $230^{\circ} \mathrm{C}$ and holding for $1 \mathrm{~h}$.

2. Heating from $230^{\circ} \mathrm{C}$ to $250^{\circ} \mathrm{C}$ and holding for $2 \mathrm{~h}$.

3. Heating from $250^{\circ} \mathrm{C}$ to $280^{\circ} \mathrm{C}$ and holding for $2 \mathrm{~h}$.

The heating rate was kept constant $\left(1{ }^{\circ} \mathrm{C} / \mathrm{min}\right)$, while the cooling segment followed the cooling rate of the furnace until room temperature. 
The cured fibers were carbonized in a tube furnace (in argon gas) to thermally process the fibers at $850{ }^{\circ} \mathrm{C}, 1000^{\circ} \mathrm{C}$, and $1250{ }^{\circ} \mathrm{C}$, and holding times 1,4 , and $8 \mathrm{~h}$, respectively. The heating rate was kept constant $\left(1.5^{\circ} \mathrm{C} \mathrm{min}^{-1}\right)$.

Fiber morphology and dimensions were characterized using a scanning electron microscope (SEM) coupled with ImageJ software [26,27]. Mechanical properties of different heat-treated fibers were carried out by cutting the fibers mat into small strips (parallel to the fibers longitudinal direction). The fibers mat dimensions were measured by connecting the tension stage to optical microscope.

X-ray diffraction (RIGAKU, Tokyo, Japan) was utilized to examine the phase formation. The X-ray parameters included $40 \mathrm{kV}$, a current of $44 \mathrm{~mA}, \mathrm{CuK} \alpha$ radiation $\left(\lambda=1.541 \mathrm{~A}^{\circ}\right)$, and a scan rate of $1 \mathrm{deg} / \mathrm{min}$. To complement the X-ray data, Renishaw in-Via Raman Microscope with $633 \mathrm{~nm}$ laser was used. Oxidation resistance test was performed using thermal gravity analysis (TGA, Q500, TA Instruments, New Castle, DE, USA).

\section{Results and Discussion}

\subsection{Scanning Electron Microscopy (SEM)}

To understand the morphological changes during heat treatments, SEM characterization was carried out for all fibers, subjected to different temperatures (Figure 1). As-spun fibers were straight and regular with limited segregation of Si nano-particles to the surface. After heat treatment, the fibers begun to shrink due to the evaporation of volatile compounds. The reduction in fiber size lowers their ability to hold a. The fibers size reduction lowers their ability in holing a large amount of nano-particles and most of the silicon migrates to the fibers surface, which forms a protective SiC layer. In addition, the fibers become wavy with increasing the carbonization temperature.

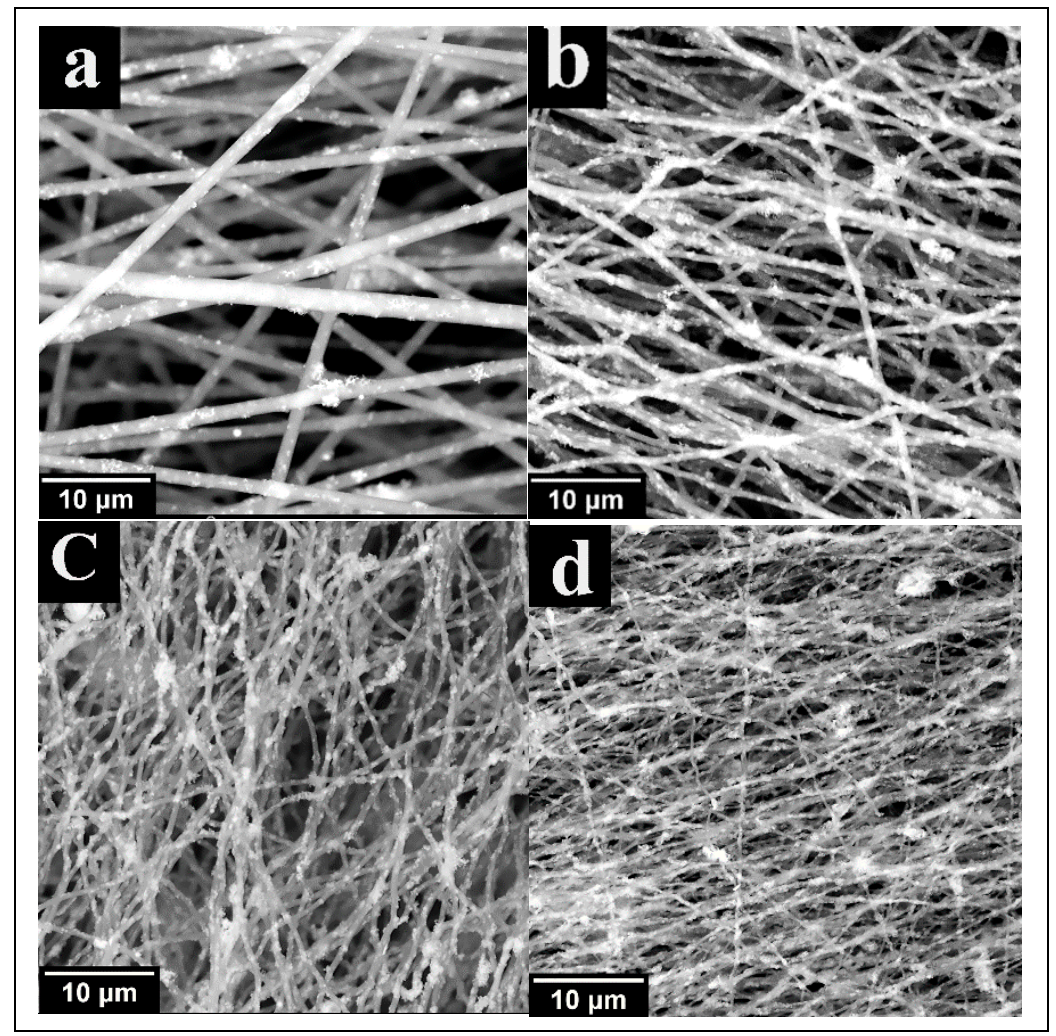

Figure 1. Scanning electron microscope (SEM) graphs of treated fibers (holding time $4 \mathrm{~h}$ ) at (a) $25^{\circ} \mathrm{C}$, (b) $850{ }^{\circ} \mathrm{C}$, (c) $1000^{\circ} \mathrm{C}$, (d) $1250{ }^{\circ} \mathrm{C}$. 
Average values from the characterization of 20 fibers was estimated using ImageJ software and the results are shown in Figure 2.

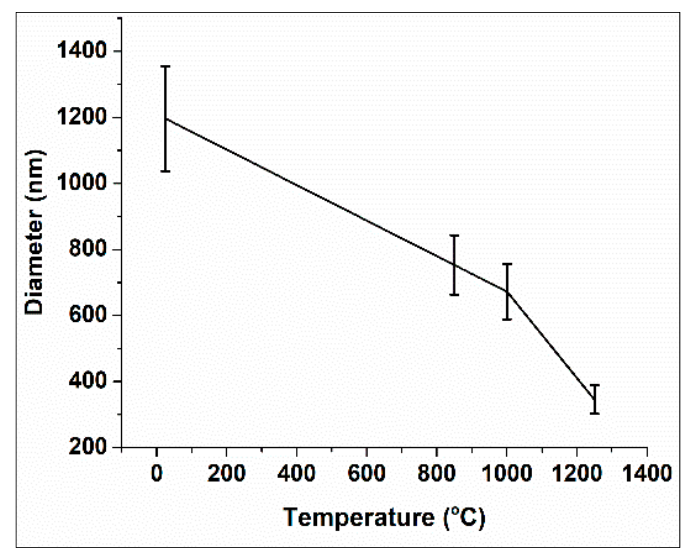

Figure 2. Relationship between fibers diameter and heat treatment temperature. Data points correspond to the average from 20 fibers. Error bars correspond to one standard deviation with respect to the average value.

\subsection{Nano-Fibers Structural Examinations}

X-ray diffraction was used to confirm and track $\mathrm{SiC}$ formation. In general, $\mathrm{SiC}$ has around 200 polytypes, which are called polymorphs [28]. The two common crystalline forms of SiC are cubic $(\beta-\mathrm{SiC})$ and hexagonal $(\alpha-\mathrm{SiC})$ forms. To identify various phases in XRD test, the interatomic spacing was calculated using the Bragg equation [29] as:

$$
\lambda=2 \mathrm{~d} \sin \theta
$$

where $\lambda$ is the wavelength of $\mathrm{X}$-ray $\left(1.5418 \mathrm{~A}^{\circ}\right), \mathrm{d}$ is interlayer distance, and $\theta$ is diffraction angle.

$X$-ray results of treated nano-fibers at different temperatures are shown in Figure 3a. For fibers treated at temperatures $1000^{\circ} \mathrm{C}$ and below, the fibers have three main domains, which were carbon, $\mathrm{SiC}$, and silicon. This means that $\mathrm{SiC}$ has begun to form at temperatures as low as $850^{\circ} \mathrm{C}$, but it was not enough to convert all silicon into $\mathrm{SiC}$. Furthermore, increasing the holding times at lower temperatures did not help in reacting the remaining $\mathrm{Si}$ (Figure $3 b$ ). It is obvious that longer holding times improved the carbon structures in the fibers as the hump around $2 \theta=26^{\circ}$ became more characteristics toward longer times, but it does not affect the $\mathrm{SiC}$ to $\mathrm{Si}$ amounts. Carbonization at elevated temperatures (more than $1250^{\circ} \mathrm{C}$ ) was enough to convert all $\mathrm{Si}$ to $\mathrm{SiC}$, which was confirmed by the X-ray results. At this temperature, the $\mathrm{SiC}$ major peaks were detected at $2 \theta=35.5^{\circ}$ and $72^{\circ}$ [30], which belonged to an interatomic spacing $\mathrm{d}_{111}=2.51, \mathrm{~d}_{220}=1.53$, and $\mathrm{d}_{311}=1.309$, respectively. 


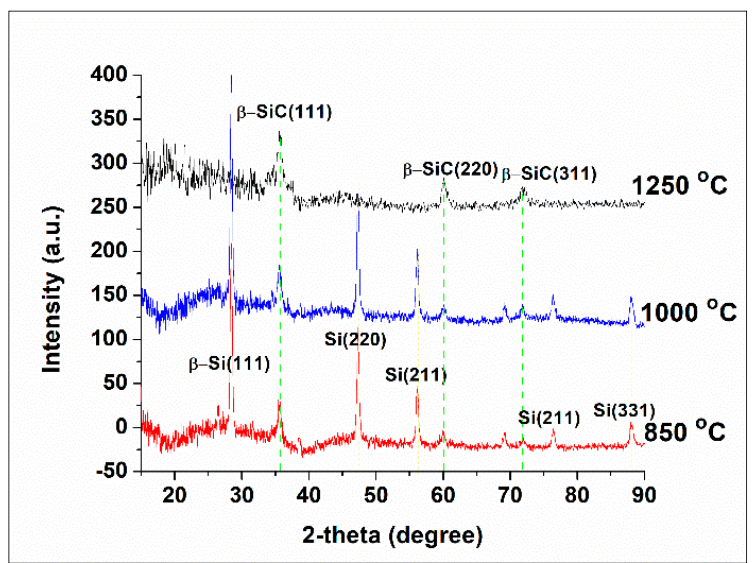

(a)

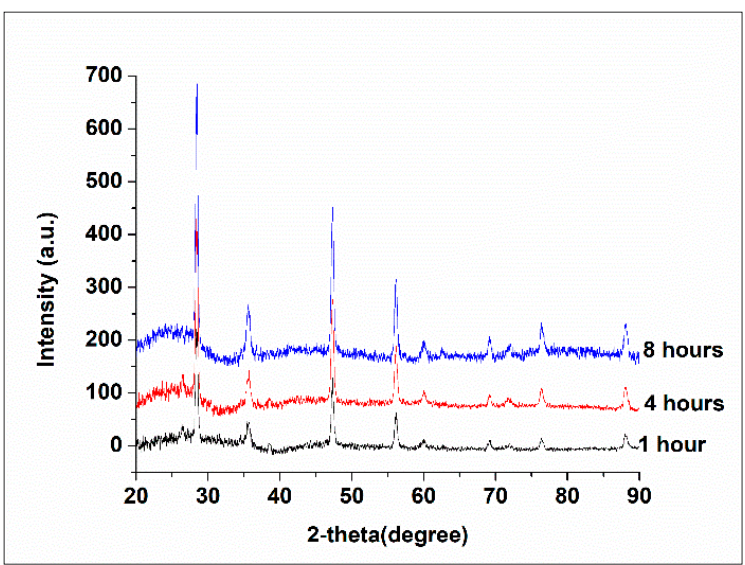

(b)

Figure 3. X-ray results of nano-fibers mat heat treated at (a) three distinct temperatures and one hour holding time, (b) $1000^{\circ} \mathrm{C}$ at three distinct holding times.

Raman spectroscopy is another powerful tool for characterizing the structure of carbon-based materials. Nano-fibers measurements were done at three different temperatures, as shown in Figure 4. The two main peaks around at 1352 and $1588 \mathrm{~cm}^{-1}$ are related to D and G band [31], respectively. Such peaks describe the molecular picture of carbon materials. The $\mathrm{D}$ band represents the defect in carbon structure or low ordered carbon structure in graphite domain, which means that the $\mathrm{D}$ band is characteristic of $\mathrm{SP}^{3}$ hybridization. On the other hand, $\mathrm{G}$ band represents $\mathrm{SP}^{2}$ hybridization in graphitic structure [32]. In addition, one of the important ratios in Raman spectroscopy is D to $G$ ratio $\left(\mathrm{I}_{\mathrm{D}} / \mathrm{I}_{\mathrm{G}}\right)$, which indicates the degree of graphitizability. From Figure 4 , the $\mathrm{I}_{\mathrm{D}} / \mathrm{I}_{\mathrm{G}}$ is inversely related to the heat treatment temperature. The ratio for higher temperatures showed a lower ratio, which means a better graphite structure. In addition, the highest heat treatment temperature $\left(1250^{\circ} \mathrm{C}\right)$ showed a $2 \mathrm{D}$ peak around $2750 \mathrm{~cm}^{-1}$.

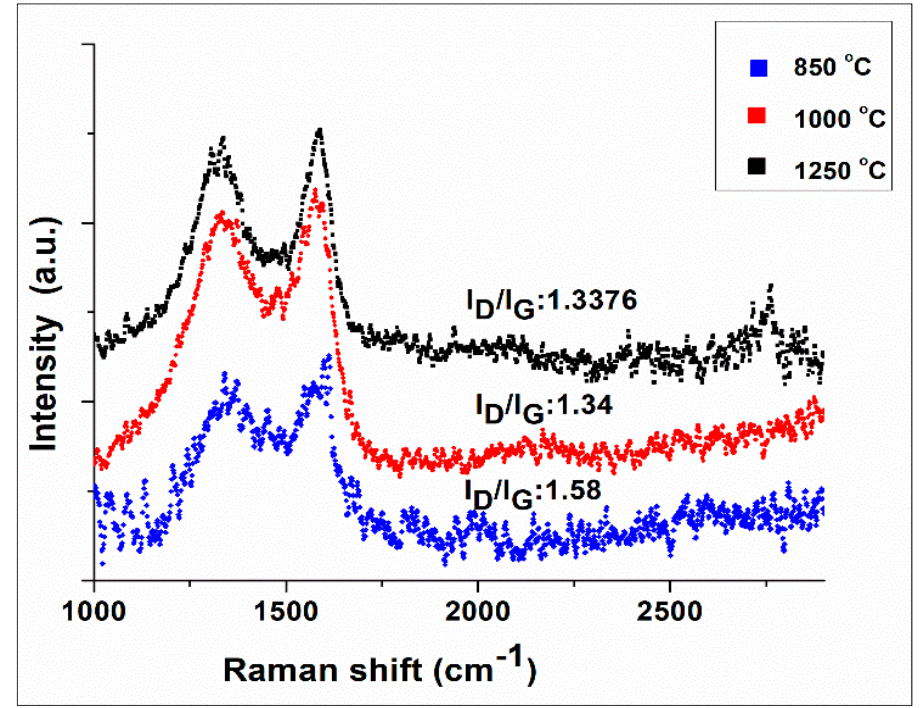

Figure 4. Raman spectroscopy of carbon fibers at three distinct temperatures.

\subsection{Thermogravimetric Analysis (TGA)}

TGA results for carbonized PAN-silicon nano-fibers at different temperatures and holding times are shown in Figure 5. After carbonization, the fibers exposed to the oxidative environment to measure their thermal resistance. To do so, the TGA test was conducted in the air with a heating rate of 
$10^{\circ} \mathrm{C} / \mathrm{min}$ from room temperature up to $800^{\circ} \mathrm{C}$. The TGA results are summarized in Table 1 . It was found that the carbonized fibers at $850{ }^{\circ} \mathrm{C}$ showed the lowest oxidation resistance and char yield. Carbonized fibers at higher temperatures showed a noticeable improvement in oxidation resistance and char yield. This confirms the effect of $\mathrm{SiC}$ phase growth at high temperatures in improving the carbon fibers oxidation resistance. TGA results (Figure 5) showed that the oxidation resistance of the fibers doubled due to increasing the holding time from $4 \mathrm{~h}$ to $8 \mathrm{~h}$. The reason behind the significant improvement explained by a previously published study regarding to the silicon particle distribution [33]. It was confirmed experimentally using TEM (Figure 6a) and numerically that most of the large silicon nano-particles were located on fibers skin and the small particles were distributed randomly. This means that the intensity of silicon, initially, on the wall was higher than the center Figure $6 \mathrm{~b}$. Silicon atoms began to combine with $\mathrm{C}$ to form $\mathrm{SiC}$ around 850, which results in the consumption of $\mathrm{Si}$, as shown in Figure $6 \mathrm{c}$,d. After $1250{ }^{\circ} \mathrm{C}$, the whole silicon was consumed and converted to $\mathrm{SiC}$ Figure $6 \mathrm{e}-\mathrm{g}$ ). The long holding times (Figure 6f) showed the highest oxidation resistance as the $\mathrm{SiC}$ formed a continuous silicon carbide coating layer in addition to the reinforcing effect within the fibers. TGA results confirm that the current method is an excellent and cheap way of protecting carbon fibers. Prakash et al. [34] improved the oxidation resistance of carbon fibers by achieving $16 \%$ char after coating $\mathrm{CFs}$ with $\mathrm{SiC}$ nanowires as compared with $0 \%$ char for uncoated carbon fibers. Zhou et al. [35] improved the carbon fibers oxidation resistance by growing silicon carbide on carbon fibers using catalysis chemical vapor deposition (CCVD), which increased the char yield to around $40 \%$. In our observation, we have maximum $60 \%$ char for hybrid carbon-SiC nano-fibers.

Table 1. Influence of heat treatment temperature and soaking time on hybrid carbon fibers char yield.

\begin{tabular}{ccc}
\hline Heat Treatment Temperature $\left({ }^{\circ} \mathbf{C}\right)$ & Holding Time (Hours) & Char Yield (\%) \\
\hline 850 & 1 & 29 \\
1000 & 1 & 33 \\
\hline & 1 & 37 \\
1250 & 4 & 41 \\
& 8 & 62 \\
\hline
\end{tabular}

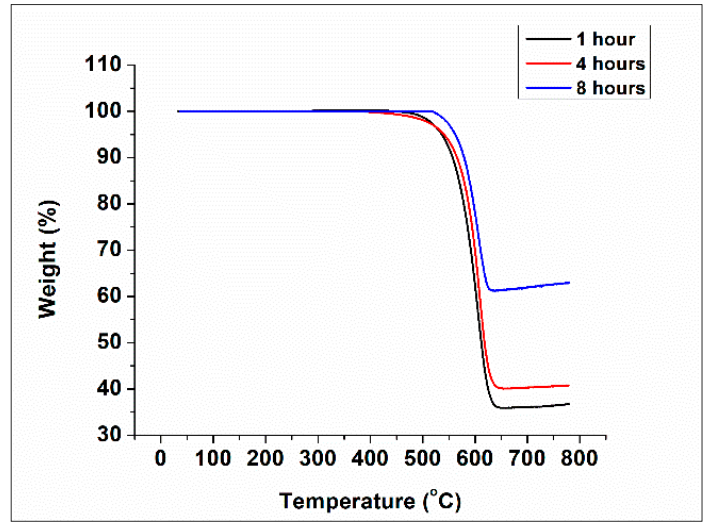

Figure 5. Thermal gravity analysis (TGA) curves of hybrid carbon fibers at different soaking times at $1250{ }^{\circ} \mathrm{C}$. 


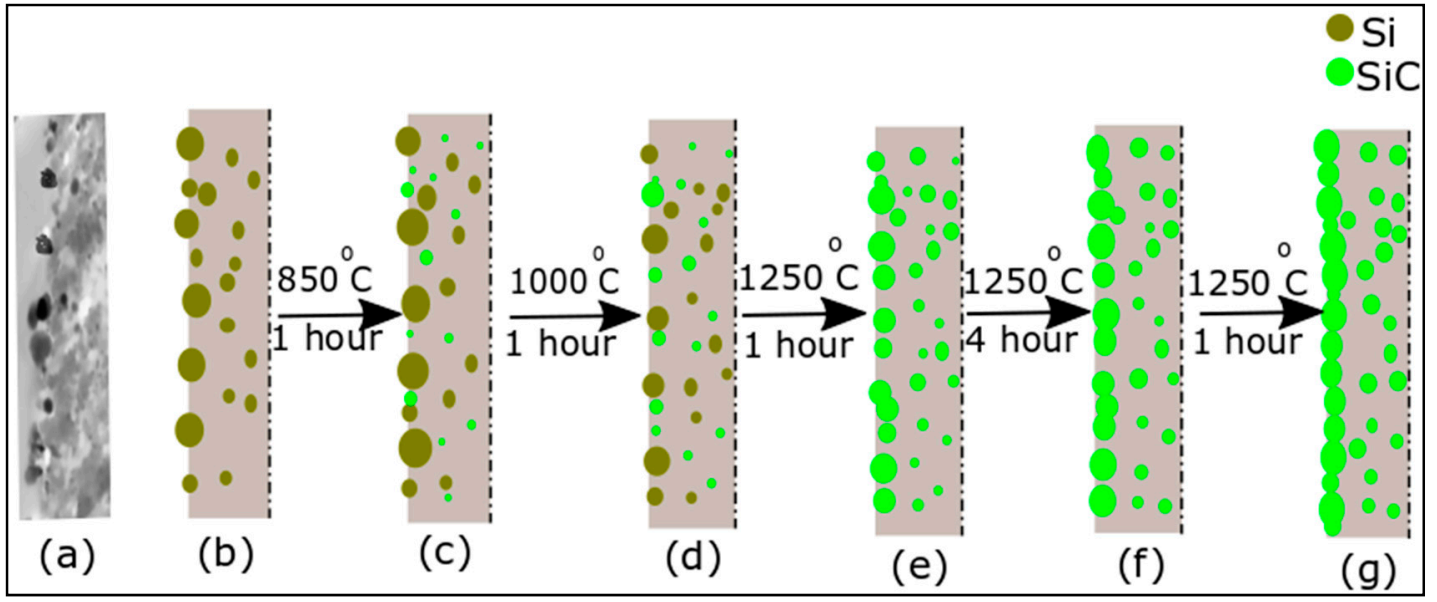

Figure 6. $\mathrm{SiC}$ nucleation and growth of $\mathrm{SiC}$ phase from silicon and carbon phases (a) TEM image of as-spun PAN-Si nano-fibers, (b) as-spun PAN-Si nano-fibers illustration, (c) SiC nucleation, (d) SiC growth, (e) conversion of all $\mathrm{Si}$ to $\mathrm{SiC}$, (f) $\mathrm{SiC}$ grain coarsening, (g) overlapping the adjacent $\mathrm{SiC}$ grains on the fibers wall forming protective ceramic coating

\subsection{Mechanical Test}

The mechanical properties of fiber mats instead of single fibers were used to avoid the challenges that are related to single fibers measurements. The fibers mat consisting of several microns thick was cut into strips to measure the fibers tensile strength. The effect of carbonization temperature on fibers mechanical properties was measured and is shown in Figure 7. The tensile strength increased from $10 \mathrm{MPa}$ to $21 \mathrm{MPa}$ after carbonizing the material to $850^{\circ} \mathrm{C}$. After this temperature, the strength of carbonized samples begun to decline due to ceramic phase formation, which has lower strength. Slope of the stress-strain curve showed a continuous increase with increasing the temperature due to the $\mathrm{SiC}$ growth which gives the material more ceramic character.

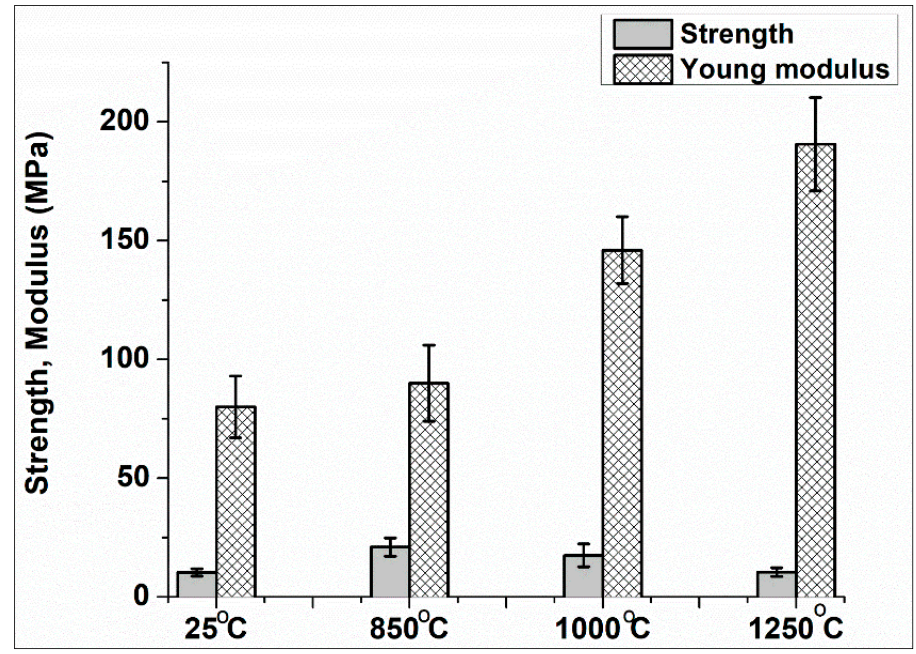

Figure 7. The relationship between mechanical properties and heat treatment temperature.

\section{Conclusions}

Polyacrylonitrile (PAN) and silicon (Si) nano-particles were used to fabricate Carbon-Silicon Carbide (C-SiC) hybrid nano-fibers. The heat treatment temperatures and holding times played a key role in changing the microstructure and the resulting thermal and mechanical properties. Complete conversion of silicon to $\mathrm{SiC}$ happened at $1250^{\circ} \mathrm{C}$, which means that, below this temperature, three 
phases co-exist ( $\mathrm{SiC}, \mathrm{Si}$, and $\mathrm{C}$ ), as confirmed from $\mathrm{X}$-ray results. Therefore, the char yield was boosted with increasing the carbonization temperatures and soaking time due to $\mathrm{SiC}$ phase growth, which works as coating and reinforcing phase. An excellent char yield around $60 \%$ was recorded for carbon hybrid fibers with $8 \mathrm{~h}$ holding time at $1250{ }^{\circ} \mathrm{C}$. Such observation provides a high oxidation protection for carbon fibers with low cost. Furthermore, the slope of the stress-strain curve increased its values with raising the heat treatment temperatures; however, the highest strength was recorded for lower carbonization temperature.

Author Contributions: S.M.N.A. performed and designed the experiment, analyzed the data, and provided the draft manuscript. K.L. supervised the work, reviewed and edited the manuscript.

Funding: This research received no external funding.

Conflicts of Interest: The authors declare no conflict of interest.

\section{References}

1. Tong, Y.; Wang, X.; Su, H.; Xu, L. Oxidation kinetics of polyacrylonitrile-based carbon fibers in air and the effect on their tensile properties. Corros. Sci. 2011, 53, 2484-2488. [CrossRef]

2. Park, S.-J.; Heo, G.-Y. Precursors and Manufacturing of Carbon Fibers BT_Carbon Fibers; Park, S.-J., Ed.; Springer: Dordrecht, The Netherlands, 2015; pp. 31-66. ISBN 978-94-017-9478-7.

3. Huang, X. Fabrication and Properties of Carbon Fibers. Materials 2009, 2, 2369-2403. [CrossRef]

4. Lu, P.; Huang, Q.; Mukherjee, A.; Hsieh, Y.-L. SiCO-doped Carbon Fibers with Unique Dual Superhydrophilicity/Superoleophilicity and Ductile and Capacitance Properties. ACS Appl. Mater. Interfaces 2010, 2, 3738-3744. [CrossRef]

5. Fukuoka, H.; Ueno, S.; Aramata, M.; Okada, T.; Hamaya, N.; Maeda, T. Graphite-Silicon Carbide Composite and Making Method. U.S. Patent 12/055985, 2 October 2008. [CrossRef]

6. Feng, L.; Xie, N.; Zhong, J. Carbon Nanofibers and Their Composites: A Review of Synthesizing, Properties and Applications. Materials 2014, 7, 3919-3945. [CrossRef] [PubMed]

7. De Rosa, I.M.; Sarasini, F.; Sarto, M.S.; Tamburrano, A. EMC Impact of Advanced Carbon Fiber/Carbon Nanotube Reinforced Composites for Next-Generation Aerospace Applications. IEEE Trans. Electromagn. Compat. 2008, 50, 556-563. [CrossRef]

8. Al-Qureshi, H.A. Automobile leaf springs from composite materials. J. Mater. Process. Technol. 2001, 118, 58-61. [CrossRef]

9. Tarfaoui, M.; El Moumen, A.; Lafdi, K. Progressive damage modeling in carbon fibers/carbon nanotubes reinforced polymer composites. Compos. Part B Eng. 2017, 112, 185-195. [CrossRef]

10. Tual, N.; Carrere, N.; Davies, P.; Bonnemains, T.; Lolive, E. Characterization of sea water ageing effects on mechanical properties of carbon/epoxy composites for tidal turbine blades. Compos. Part A Appl. Sci. Manuf. 2015, 78, 380-389. [CrossRef]

11. Ali, A.H.; Mohamed, H.M.; Benmokrane, B.; ElSafty, A. Theory-based approaches and microstructural analysis to evaluate the service life-retention of stressed carbon fiber composite strands for concrete bridge applications. Compos. Part B Eng. 2019, 165, 279-292. [CrossRef]

12. Pervaiz, M.; Sain, M.M. Carbon storage potential in natural fiber composites. Resour. Conserv. Recycl. 2003, 39, 325-340. [CrossRef]

13. Luan, C.; Yao, X.; Liu, C.; Lan, L.; Fu, J. Self-monitoring continuous carbon fiber reinforced thermoplastic based on dual-material three-dimensional printing integration process. Carbon N. Y. 2018, 140, 100-111. [CrossRef]

14. Liu, C.; Lafdi, K. Fabrication and characterization of carbon nanofibers from polyacrylonitrile/pitch blends. J. Appl. Polym. Sci. 2017, 134, 45388. [CrossRef]

15. Xu, Z.; Gao, C. Graphene fiber: A new trend in carbon fibers. Mater. Today 2015, 18, 480-492. [CrossRef]

16. Morgan, B.A.B.; Matters, M.; Issue, V. Polymer-Clay Nanocomposites : Design and Application of Multi-Functional Materials. Mater. Matters 2011, 2, 20-25.

17. $\mathrm{Xu}, \mathrm{F}$; $\mathrm{Wu}, \mathrm{D} . ; \mathrm{Fu}, \mathrm{R}$.; Wei, B. Design and preparation of porous carbons from conjugated polymer precursors. Mater. Today 2017, 20, 629-656. [CrossRef] 
18. Al-Ajrah, S.; Lafdi, K.; Liu, Y.; Le Coustumer, P. Fabrication of ceramic nanofibers using polydimethylsiloxane and polyacrylonitrile polymer blends. J. Appl. Polym. Sci. 2017, 135, 45967. [CrossRef]

19. Schöppl, O.; Ruess, G.; Lengauer, W.; Liersch, A.; Köttritsch, H. Polymer Precursor Ceramics and Their Applications; SKF Science Days: Steyr, Austria, 2004.

20. Ji, L.; Jung, K.-H.; Medford, A.J.; Zhang, X. Electrospun polyacrylonitrile fibers with dispersed Si nanoparticles and their electrochemical behaviors after carbonization. J. Mater. Chem. 2009, 19, 4992-4997. [CrossRef]

21. Huang, Z.M.; Zhang, Y.Z.; Kotaki, M.; Ramakrishna, S. A review on polymer nanofibers by electrospinning and their applications in nanocomposites. Compos. Sci. Technol. 2003, 63, 2223-2253. [CrossRef]

22. Shao, C.; Kim, H.-Y.; Gong, J.; Ding, B.; Lee, D.-R.; Park, S.-J. Fiber mats of poly(vinyl alcohol)/silica composite via electrospinning. Mater. Lett. 2003, 57, 1579-1584. [CrossRef]

23. Han, P.; Yuan, T.; Yao, L.; Han, Z.; Yang, J.; Zheng, S. Copper Nanoparticle-Incorporated Carbon Fibers as Free-Standing Anodes for Lithium-Ion Batteries. Nanoscale Res. Lett. 2016, 11, 172. [CrossRef]

24. Dadvar, S.; Tavanai, H.; Morshed, M. Fabrication of nanocomposite PAN nanofibers containing $\mathrm{MgO}$ and Al2O3 nanoparticles. Polym. Sci. Ser. A 2014, 56, 358-365. [CrossRef]

25. Lee, S.-H.; Yun, S.-M.; Kim, S.J.; Park, S.-J.; Lee, Y.-S. Characterization of nanoporous $\beta$-SiC fiber complex prepared by electrospinning and carbothermal reduction. Res. Chem. Intermed. 2010, 36, 731-742. [CrossRef]

26. Kancheva, M.; Toncheva, A.; Manolova, N.; Rashkov, I. Enhancing the mechanical properties of electrospun polyester mats by heat treatment. Express Polym. Lett. 2015, 9, 49-65. [CrossRef]

27. Rošic, R.; Pelipenko, J.; Kocbek, P.; Baumgartner, S.; Bešter-Rogač, M.; Kristl, J. The role of rheology of polymer solutions in predicting nanofiber formation by electrospinning. Eur. Polym. J. 2012, 48, 1374-1384. [CrossRef]

28. Chikvaidze, G.; Mironova-Ulmane, N.; Plaude, A.; Sergeev, O. Investigation of silicon carbide polytypes by Raman spectroscopy. Latv. J. Phys. Tech. Sci. 2014, 51, 51-57. [CrossRef]

29. Kim, S.Y.; Kim, B.-H.; Yang, K.S.; Kim, K.-Y. The formation of silica nanoparticles on the polyacrylonitrile-based carbon nanofibers by graphene via electrospinning. Mater. Lett. 2012, 71, 74-77. [CrossRef]

30. Yue, Y. Synthesis of Silicon Carbide Fibers From Polycarbosilane by Electrospinning Method. Master's Thesis, Clemson University, Clemson, SC, USA, 2014.

31. Kaniyoor, A.; Ramaprabhu, S. A Raman spectroscopic investigation of graphite oxide derived graphene. AIP Adv. 2012, 2, 32183. [CrossRef]

32. Lu, P.; Huang, Q.; Mukherjee, A.; Hsieh, Y.-L. Effects of polymer matrices to the formation of silicon carbide (SiC) nanoporous fibers and nanowires under carbothermal reduction. J. Mater. Chem. 2011, 21, 1005-1012. [CrossRef]

33. Al-Ajrash, S.M.N.; Lafdi, K.; Vasquez, E.S.; Chinesta, F.; Le Coustumer, P. Experimental and Numerical Investigation of the Silicon Particle Distribution in Electrospun Nanofibers. Langmuir 2018, 34, 7147-7152. [CrossRef]

34. Prakash, J.; Dasgupta, K.; Kumar, B.; Ghosh, S.K.; Chakravartty, J.K. Role of SiC nanowire coating on oxidation behavior of carbon fibers: Kinetic and thermodynamic study. Surf. Coat. Technol. 2014, 259, 637-646. [CrossRef]

35. Zhou, W.; Long, L.; Xiao, P.; Li, Y.; Luo, H.; Hu, W.; Yin, R. Silicon carbide nano-fibers in-situ grown on carbon fibers for enhanced microwave absorption properties. Ceram. Int. 2017, 43, 5628-5634. [CrossRef]

(C) 2019 by the authors. Licensee MDPI, Basel, Switzerland. This article is an open access article distributed under the terms and conditions of the Creative Commons Attribution (CC BY) license (http://creativecommons.org/licenses/by/4.0/). 